
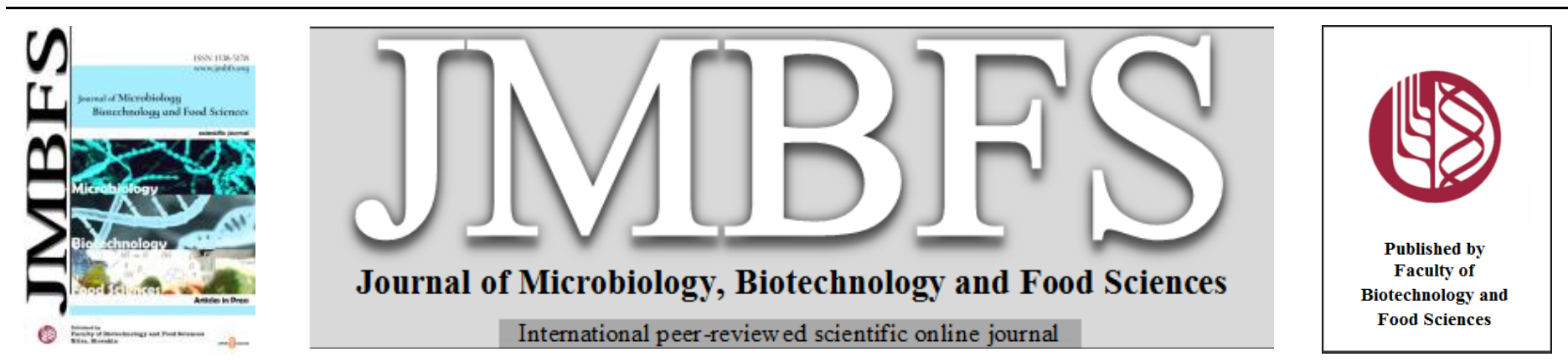

\title{
MICROENCAPSULATION OF BIFIDOBACTERIUM LACTIS Bi-07 WITH GALACTOOLIGOSACCHARIDES USING CO-EXTRUSION TECHNIQUE
}

\author{
Pui Yin Lai ${ }^{l}$, Yu Hsuan How ${ }^{l}$, Liew Phing Pui ${ }^{1 *}$ \\ Address(es): Liew Phing Pui, \\ ${ }^{1}$ UCSI University, Faculty of Applied Sciences, Department of Food Science with Nutrition, No. 1, Jalan Menara Gading, Taman Connaught, Cheras, 56000 Kuala \\ Lumpur, Malaysia. $+603-9101880$.
}

*Corresponding author: puilp@ucsiuniversity.edu.my

https://doi.org/10.55251/jmbfs.2416

\section{ARTICLE INFO}

Received 6. 12. 2019

Revised 20.1. 2022

Accepted 20. 1.2022

Published 1. 6. 2022

Regular article OPEN $\partial_{\text {ACCESS }}$

\begin{abstract}
Probiotics play an important role in human gut health. However, it remains a challenge to maintain the viability of probiotics throughout the gastrointestinal transit. Hence, this study aimed to microencapsulate Bifidobacterium lactis Bi-07 with galactooligosaccharides (GOS) using the co-extrusion technique. Optimization of calcium chloride $(1.0 \% \mathrm{w} / \mathrm{v}$ to $3.0 \% \mathrm{w} / \mathrm{v})$ and $\mathrm{GOS}$ concentration $(1.0 \% \mathrm{w} / \mathrm{v}$ to $5.0 \%$ w/v) were performed in the encapsulation of $B$. lactis Bi-07 based on bead size and microencapsulation efficiency. The study found that microbead prepared with $1.5 \%(\mathrm{w} / \mathrm{v})$ sodium alginate, $2.0 \%(\mathrm{w} / \mathrm{v})$ calcium chloride and $3.0 \%(\mathrm{w} / \mathrm{v})$ GOS showed the highest microencapsulation efficiency. The size of the bead produced was $735.69 \mu \mathrm{m}$ with the highest microencapsulation efficiency of more than 94\%. Besides, the microencapsulation efficiency and bead size were compared between B. lactis Bi-07 beads with or without GOS. Results showed that the encapsulated B. lactis Bi-07 with GOS was had a larger bead size and lower microencapsulation efficiency than encapsulated probiotic cells without GOS. Furthermore, the encapsulated B. lactis Bi-07 and free cells were subjected to simulated gastrointestinal treatment where the cell viability was evaluated. Encapsulated B. lactis Bi-07 with GOS showed higher cell viability than encapsulated B. lactis Bi-07 without GOS and free cells after the simulated gastrointestinal treatment. The viable cell count of encapsulated B. lactis Bi-07 with GOS remained more than $10^{7} \mathrm{CFU} / \mathrm{mL}$. This showed that the optimized encapsulated B. lactis Bi- 07 with GOS could survive the human gastrointestinal to confer health benefits and the potential to be incorporated into functional foods.
\end{abstract}

\section{INTRODUCTION}

There is a high demand for consumers for functional foods as a concern for a healthy lifestyle is becoming an important factor for consumers. Functional foods are foods or beverages that provide physiological benefits due to the presence of active substances such as probiotics (Rodríguez-Huezo et al., 2007). The term probiotic is defined as the living organisms that confer health benefits when administered in appropriate amounts (Cook $\boldsymbol{e t}$ al., 2012). Probiotics are mostly incorporated into dairy products such as yoghurt, milk powder, ice cream, and cheese (Ranadheera et al., 2017). Food containing probiotic bacteria should have at least $10^{7}$ colony forming unit $(\mathrm{CFU} / \mathrm{mL})$ in order to ensure a sufficient amount to reach the large intestine (Nazzaro et al., 2009).

Many research studied on Lactobacillus and Bifidobacterium strains, such as Lactobacillus acidophilus, Lactobacillus paracasei, and Bifidobacterium animalis subsp. lactis which are gram-positive, non-spore forming, lactic acid-producing bacteria (Morovic et al., 2017). B. lactis Bi-07 is a lactic acid bacteria that tend to have a higher abundance in colonic microbiota (Lyra et al., 2012). It has been widely studied for its beneficial effect on gastrointestinal and colon health. Yang et al. (2008) and Favretto et al. (2013) reported that B. lactis was effective in relieving constipation. Besides, studies have shown that consumption of B. lactis Bi-07 enhances immune function and gut microbiota in healthy elderly adults and significantly improve distention and bloating in patients with functional bowel disorder (Maneerat et al., 2013; Ringel et al., 2011).

Probiotics play a main role in human health such as digestion and improve nutrient absorption (Annan et al., 2008). However, the efficacy of probiotics depends on how well they can adapt to the acidic environment of the stomach and gastrointestinal tract. The survivability of probiotics in the intestines is importan as nutrients are absorbed in the intestines. Unfortunately, most of the probiotics lack the ability to survive in high quantity due to low $\mathrm{pH}$ in gastric juice and exposure to oxygen, which can affect the effectiveness in most functional foods (Sagheddu et al., 2018; Talwalkar \& Kailasapathy, 2004). Microencapsulation is a technique in which the probiotics are incorporated into encapsulating materials such as sodium alginate, chitosan, pectin, and carrageenan to protect probiotics from the harsh conditions during gastrointestinal transit or storage in food matrices
(Afzaal et al., 2019; Bepeyeva et al., 2017; Chan \& Pui, 2020; Lai et al., 2020; Yong et al., 2020).

Co-extrusion microencapsulation is a recent technology, in which the liquid core is pumped through the inner orifice and the liquid wall material is pumped through the outer orifice. The extruded solutions were then broken into droplets and capsules are formed (Chew et al., 2015). Siang et al. (2019) applied the coextrusion technique on the encapsulation of Lactobacillus rhamnosus GG with isomalto-oligosaccharides using poly L-lysine as a coating. Moreover, Yee $\boldsymbol{e t}$ al. (2019) and Ng et al. (2019) also performed co-extrusion of L. acidophilus NCFM with mannitol and Lactobacillus plantarum $299 \mathrm{v}$ with oligofructose, respectively. The most commonly used encapsulating material is sodium alginate which has a highly versatile matrix, biocompatible and non-toxic for the protection of active components (Goh et al., 2012). It is the most polysaccharide used as encapsulating material of lactic acid bacteria due to ease of handling, low cost and help to increase the viability of bacteria in adverse condition (Burgain et al., 2011). The combination of alginate with prebiotics enhanced protection for probiotics in food products. Prebiotics can be defined as non-digestible substances that resist hydrolysis in the stomach and small intestine. It plays an important role in improving the probiotic activity (Sathyabama et al., 2014). Galactooligosaccharides (GOS) is a non-digestible oligosaccharide that is often found in dairy products, bean, and vegetables. It is recognized as safe to use in food application as a sweetener (Hong et al., 2016; Roberfroid et al., 2010). GOS is a potential prebiotic for B. lactis as it was reported to enhance the growth of Bifidobacterium species by various studies (Goulas et al., 2009; Hinz et al., 2004; Hung \& Lee, 2002). Furthermore, it is also recognized as clinical evidence in improving digestive health and the immune system (Sangwan et al., 2011).

The harsh conditions of the gastrointestinal tract often resulted in a low number of probiotic cells reaching the large intestine (Prakash et al., 2011). Therefore, microencapsulation of probiotics is important to ensure high numbers of cells survived through the gastrointestinal tract in order to confer health benefits to human (WHO \& FAO, 2002). To date, the microencapsulation of B. lactis Bi-07 with GOS using co-extrusion technique has yet to be explored by other researchers. Hence, the objective of this study is to improve the survivability of probiotic $B$ lactis in the gastrointestinal environment through the addition of prebiotic GOS 
and microencapsulation using co-extrusion method. The prebiotic effect of GOS on the encapsulation of $B$. lactis and the viability of $B$. lactis $\mathrm{Bi}-07$ microbeads after exposure to simulated gastrointestinal juices were evaluated.

\section{MATERIAL AND METHODS}

\section{Isolation of bacterial cell culture}

Pure mixed Lactobacillus acidophilus NCFM and Bifidobacterium lactis $\mathrm{Bi}-07$ powder (Kordel's, USA) was obtained from AA Pharmacy Taman Connaught, KL. Firstly, $2 \mathrm{~g}$ of mixed B. lactis Bi-07 and Lacidophilus NCFM powder was cultivated in $100 \mathrm{~mL}$ of autoclaved Bifidus Selective Medium (BSM) broth (HiMedia, India). The culture was then incubated at $37^{\circ} \mathrm{C}$ for 24 hours in anaerobic condition to allow bacteria growth. After 24 hours, the streak plate method was used to isolate the bacteria. One loop of bacteria cell culture was streaked on Bifidobacterium Agar, Modified with Bifidobacterium Selective Supplement (FD285) (HiMedia, India). The petri dish with cell culture was then incubated at $37^{\circ} \mathrm{C}$ for 48 hours to allow single colony growth (Nualkaekul et al., 2012).

\section{Preparation of cell culture}

A single colony of $\mathrm{B}$. lactis $\mathrm{Bi}-07$ was transferred to BSM broth and incubated for 24 hours at $37^{\circ} \mathrm{C}$ (Nualkaekul et al., 2012). After 24 hours, the cells were then harvested by centrifugation at $3200 \mathrm{rpm}$ (Eppendorf 5804R, Germany) for 15 minutes at $4^{\circ} \mathrm{C}$. After centrifugation, the supernatant was discarded and the pellets were washed twice with $0.1 \mathrm{M}$ phosphate buffer saline (PBS). The pellets were resuspended in $50 \mathrm{~mL}$ of PBS. The final cell culture was stored at $4^{\circ} \mathrm{C}$ before microencapsulation.

\section{Optimization of calcium chloride, $\mathrm{CaCl}_{2}$}

Different concentrations of calcium chloride (R\&M Chemicals, UK) $(1.0,1.5,2.0$ 2.5 and $3.0 \% \mathrm{w} / \mathrm{v})$ were used for the optimization. The concentration of sodium alginate (R\&M Chemicals, UK) was fixed at $1.5 \%$ and the concentration of GOS (R\&M Chemicals, UK) was fixed at $3 \%$. The optimum concentration of calcium chloride was determined based on bead size and microencapsulation efficiency (Chew et al., 2015)

\section{Optimization of galactooligosaccharides (GOS)}

Different concentrations of $\operatorname{GOS}(1,2,3,4$ and $5 \% \mathrm{w} / \mathrm{v})$ were used for the optimization. To prepare GOS solution, $0.5 \mathrm{~g}, 1.0 \mathrm{~g}, 1.5 \mathrm{~g}, 2.0 \mathrm{~g}$ and $2.5 \mathrm{~g}$ GOS powder were dissolved in $25 \mathrm{~mL}$ distilled water, respectively. The mixture was gently mixed until it is fully dissolved and mixed with $25 \mathrm{~mL}$ cell suspension before using in the microencapsulation process (Chew et al., 2015).

\section{Microencapsulation of $B$. lactis Bi-07 using co-extrusion method}

Büchi Encapsulator B-390 (Büchi, Switzerland) was used to conduct microencapsulation of the co-extrusion method according to (Chew et al., 2015) with modification. The core material (B. lactis Bi-07 suspended in PBS without or with different concentration of GOS) and wall material (sodium alginate solution) were added into two separate pressured bottles connected to Büchi Encapsulator B-390 machine. Diameter for concentric nozzle (inner nozzle) and shell nozzle used was $200 \mu \mathrm{m}$ and $300 \mu \mathrm{m}$, respectively. During microencapsulation, core fluid and shell fluid were pumped simultaneously through concentric nozzle and shell nozzle by $600 \mathrm{mbar}$ of pressure, $300 \mathrm{~Hz}$ of vibration frequency, amplitude of 3 and $1.5 \mathrm{kV}$ of voltage. The microbeads formed were dropped into sterile $(0.1 \% \mathrm{w} / \mathrm{v})$ chitosan solution for 30 minutes to allow the microbeads to harden. The chitosan solution $(0.1 \% \mathrm{w} / \mathrm{v})$ was prepared by dissolving $1 \mathrm{~g}$ of chitosan into $500 \mathrm{~mL}$ of distilled water with glacial acetic acid. Different concentrations of calcium chloride $(10 \mathrm{~mL})$ and $0.5 \mathrm{~mL}$ of Tween 80 solution were also added into the chitosan solution. After 30 minutes, the microbeads were collected using a nylon sieve and dried using filter paper.

\section{Morphology and bead size}

The morphology and mean diameter of 20 randomly selected beads was determined and measured by using CX 31 optical microscope with $\mathrm{x} 40$ magnification (Olympus, Japan). The beads were placed on the stage micrometre and the size of beads were observed and recorded (Siang et al., 2019).

\section{Sequential Digestion}

Sequential digestion was performed according to Chia $\boldsymbol{e t}$ al. (2015) with slight modification. Simulated gastric juice (SGJ) was prepared by mixing $3.5 \mathrm{~mL}$ hydrochloric acid $(\mathrm{HCl})$ and $1 \mathrm{~g}$ of sodium chloride in $500 \mathrm{~mL}$ distilled water. The mixture was then adjusted to $\mathrm{pH} 2.0$ with $\mathrm{HCl}$. On the other hand, simulated intestinal juice (SIJ) was prepared by dissolving $3.4 \mathrm{~g}$ of potassium dihydrogen phosphate in $125 \mathrm{~mL}$ of distilled water and $95 \mathrm{~mL}$ of sodium hydroxide $(\mathrm{NaOH})$
The mixture was adjusted to $\mathrm{pH} 7.5$ using $\mathrm{NaOH}$ and make up the volume to 500 $\mathrm{mL}$. Both SGJ and SIJ solution were then sterilized at $121^{\circ} \mathrm{C}$ for 15 minutes and cooled to room temperature prior to the addition of $1.6 \mathrm{~g}$ of pepsin and $3 \mathrm{~g}$ of bile salt, respectively.

To evaluate the survivability of Bi-07 under simulated gastrointestinal condition, $1 \mathrm{~g}$ of beads (with or without GOS) or $1 \mathrm{~mL}$ of $\mathrm{Bi}-07$ free cells were transferred into $15 \mathrm{~mL}$ centrifuge tube containing $9 \mathrm{~mL}$ of sterile SGJ with $\mathrm{pH} 2.0$. The mixture was then mixed gently with a speed setting of $150 \mathrm{rpm}$ and was incubated at $37^{\circ} \mathrm{C}$ for 0 hour, 1 hour and 2 hours, respectively using an incubator shaker (KS 4000 i control, IKA, Germany). The Bi-07 free cell or Bi-07 beads at 0 hour function as control. For each hour, the beads or free cell were removed, respectively from the incubator shaker, followed by filtration and centrifugation under $4200 \mathrm{rpm}$ for 10 minutes at $4{ }^{\circ} \mathrm{C}$ to determine the viability of Bi-07. Beads or free cell at the second hour were then transferred from SGJ solution to sterile $\mathrm{pH} 7.5$ SIJ solution, followed by further incubation at $37^{\circ} \mathrm{C}$ for 3 hours. Similarly, at each hour, the beads or free cell in SIJ were removed by filtration and undergo centrifugation under $3200 \mathrm{rpm}$ for 10 minutes at $4^{\circ} \mathrm{C}$ (Yee et al., 2019).

After the sequential digestion was completed, the beads were filtered and rinsed with PBS to remove the remaining SIJ solution on the beads. The rinsed beads (1 g) were then being transferred into a stomacher bag (Copens Scientific, Malaysia) which contain $9 \mathrm{~mL}$ of sodium citrate solution, underwent speed setting to break the microbeads. On the other hand, for free cells, it was centrifuged at $4200 \mathrm{rpm}$ for 10 minutes, followed by discarding the supernatant and the cell pellet was rinsed twice with PBS. The cell pellet was then re-suspended in PBS for cell enumeration.

Prior to cell enumeration, the mixture was serially diluted using PBS. Aliquot of $0.1 \mathrm{~mL}$ of the mixture was pipetted onto a petri dish, followed by pouring the $50^{\circ} \mathrm{C}$ molten BSM agar onto the agar plate and swirled gently. After the BSM agar had been solidified, the agar plate was sealed properly using parafilm (Bemis, USA) and incubated at $37^{\circ} \mathrm{C}$ for 48 hours in an invert position anaerobically. The viable cell count for the beads and free cell were expressed in logarithm colony-forming unit per millimetre $(\log \mathrm{CFU} / \mathrm{mL})$ based on Equation 1 .

Viable cell count $(\mathrm{CFU} / \mathrm{mL})=$ Average number of colonies/ dilution factor $\mathrm{x}$ volume plated $(0.1 \mathrm{~mL})$

\section{Microencapsulation Efficiency (MEE)}

Microencapsulation efficiency (MEE) is defined as the measurement of the viability of cells throughout the microencapsulation process and the efficacy of entrapment (Zanjani et al., 2014). MEE was calculated according to Equation 2, where $\mathrm{N}$ is the cell count released from the microbeads and $\mathrm{N}_{0}$ is the cell count in free cells.

Microencapsulation efficiency $(\%)=\left[\mathrm{N}(\mathrm{CFU} / \mathrm{mL}) / \mathrm{N}_{0}(\mathrm{CFU} / \mathrm{mL})\right] \times 100 \%$ [2]

\section{Statistical Analysis}

All analysis was carried out in triplicates. The results were expressed as mean \pm standard deviation. Minitab Statistical Software 18.0 was used for data analysis. One-way analysis of variance (ANOVA) was carried out. The average values were compared with Tukey's post hoc test. The significant difference was set at $\mathrm{p} \leq 0.05$.

\section{RESULTS AND DISCUSSION}

\section{Optimization of concentration of calcium chloride and} galactooligosaccharides (GOS)

In this study, the concentration of calcium chloride and GOS was optimized in order to develop a good hardening solution for microbeads based on microencapsulation efficiency and bead size. Table 1 shows the effect of different concentration of calcium chloride on bead size and microencapsulation efficiency of the microencapsulated $B$. lactis $\mathrm{Bi}-07$. Throughout the optimization process, the concentration of alginate was fixed at $1.5 \%$.

Table 1 Effect of different concentration of calcium chloride on bead size and microencapsulation efficiency of the microencapsulated Bifidobacterium lactis Bi07

\begin{tabular}{lccc}
\hline $\begin{array}{l}\text { Calcium } \\
\text { chloride }(\% \\
\text { w/v })\end{array}$ & $\begin{array}{c}\text { Alginate } \\
(\% \mathbf{w} / \mathbf{v})\end{array}$ & $\begin{array}{c}\text { Diameter of } \\
\text { beads }(\boldsymbol{\mu m})\end{array}$ & $\begin{array}{c}\text { Microencapsulation } \\
\text { efficiency }(\%)\end{array}$ \\
\hline 1.0 & 1.5 & $675.33 \pm 15.92^{\mathrm{d}}$ & $85.33 \pm 5.36^{\mathrm{c}}$ \\
1.5 & 1.5 & $682.67 \pm 27.78^{\mathrm{cd}}$ & $89.33 \pm 2.89^{\mathrm{ab}}$ \\
2.0 & 1.5 & $696.00 \pm 19.76^{\mathrm{c}}$ & $91.03 \pm 3.37^{\mathrm{a}}$ \\
2.5 & 1.5 & $766.67 \pm 21.87^{\mathrm{a}}$ & $87.37 \pm 1.83^{\mathrm{bc}}$ \\
3.0 & 1.5 & $726.33 \pm 17.12^{\mathrm{b}}$ & $82.70 \pm 2.93^{\mathrm{d}}$ \\
\hline
\end{tabular}

*Data are expressed as mean \pm standard deviation (SD) followed by different superscript letter (a-d) within the same column are significantly different at $\mathrm{p} \leq 0.05$. 
Calcium chloride is necessary for the hardening process to form insoluble gel thus microencapsulation with $0 \%(\mathrm{w} / \mathrm{v})$ calcium chloride was not carried out in this study (Etchepare et al., 2015). From Table 1, it shows that the diameter of beads increased significantly $(\mathrm{p} \leq 0.05)$ as the concentration of calcium chloride increased from $1.0 \%(\mathrm{w} / \mathrm{v})$ to $2.5 \%(\mathrm{w} / \mathrm{v})$. This agrees with the findings by Rogers et al. (2013) where the bead diameter increases with the calcium chloride concentration. According to the study, higher calcium ions are present at higher calcium chloride concentration, which allows it to replace the sodium ions from sodium alginate. Hence, inter-globular cross-linking takes place instead of intraglobular cross-linking, resulting in an increased of beads diameter. However, there was a decrease in the bead size when the concentration of calcium chloride increased from $2.5 \%(\mathrm{w} / \mathrm{v})$ to $3 \%(\mathrm{w} / \mathrm{v})$. This overall result is in agreement with the findings of Smrdel $\boldsymbol{e t}$ al. (2008) who reported that the size of bead varied significantly without correlation as the calcium chloride concentration increases. This could be due to the drying of the microbeads were not controlled as they were dried using filter paper in an open environment, which resulted in inconsistent beads diameter. According to Smrdel et al. (2008), air drying may influence the shape and size of the microbeads due to water removal, which resulted in the shrinking of the microbeads.

Besides, the increase in calcium chloride concentration from $1.0 \%(\mathrm{w} / \mathrm{v})$ to $2.0 \%$ $(\mathrm{w} / \mathrm{v})$ had a significant positive effect $(\mathrm{p} \leq 0.05)$ on the microencapsulation efficiency. The encapsulated B. lactis Bi-07 displayed the highest MEE $(91.03 \%)$ when $1.5 \%(\mathrm{w} / \mathrm{v})$ sodium alginate and $2.0 \%(\mathrm{w} / \mathrm{v})$ calcium chloride were used in the microencapsulation. However, there was no further increase in MEE when $2.5 \%(\mathrm{w} / \mathrm{v})$ and $3.0 \%(\mathrm{w} / \mathrm{v})$ of calcium chloride was used. A similar result was reported by $\mathrm{Ng}$ et al. (2019), where the MEE increased when calcium chloride solution increased from $1.0 \%(\mathrm{w} / \mathrm{v})$ to $2.5(\mathrm{w} / \mathrm{v})$; and decrease in MEE when calcium chloride further increase to $3.0 \%(\mathrm{w} / \mathrm{v})$. The result is also supported by Nagpal et al. (2012) who reported that microencapsulation efficiency of ibuprofen increased when the concentration of calcium chloride increased from $2.5 \mathrm{~g}$ to $5.0 \mathrm{~g}$. However, the microencapsulation efficiency decreased when the calcium chloride concentration increases to $7.5 \mathrm{~g}$. The study states that the further increase of calcium chloride to $7.5 \mathrm{~g}$ cause an increase in viscosity which disrupted the crosslinking process during microencapsulation. Another possible explanation is that high calcium chloride concentration could damage the cell membrane by disturbing the state of cell electrolyte, thus affecting the microencapsulation efficiency (Cao et al., 2012). Furthermore, when the calcium-binding sites in the glucuronic acid chain are too saturated, it could cause damage and osmotic stress towards the microbeads, hence lowering the microencapsulation efficiency (Zam et al., 2014).

As $2.0 \%(w / v)$ calcium chloride gave the highest MEE in the first part of the optimization, the concentration was chosen and fixed for the optimization of galactooligosaccharides (GOS) concentration. Different concentration of GOS $(1 \% \mathrm{w} / \mathrm{v}$ to $5 \% \mathrm{w} / \mathrm{v})$ was used to evaluate the bead size and microencapsulation efficiency. Table 2 shows the microencapsulation efficiency and average beads diameter of the encapsulated B. lactis Bi-07 with different concentration of GOS.

Table 2 Microencapsulation efficiency and average diameter of beads encapsulated with $B$. lactis $\mathrm{Bi}-07$ using different concentration of galactooligosaccharides (GOS)

\begin{tabular}{lcccc}
\hline $\begin{array}{l}\text { Alginate } \\
(\% \text { w/v })\end{array}$ & $\begin{array}{c}\text { Calcium } \\
\text { chloride } \\
(\% \text { w/v })\end{array}$ & $\begin{array}{c}\text { GOS } \\
(\% \\
\mathbf{w} / \mathbf{v})\end{array}$ & $\begin{array}{c}\text { Diameter of } \\
\text { beads }(\boldsymbol{\mu m})\end{array}$ & $\begin{array}{c}\text { Microencapsulation } \\
\text { efficiency }(\%)\end{array}$ \\
\hline 1.5 & 2.0 & 0.0 & $683.14 \pm 7.57^{\mathrm{d}}$ & $96.28 \pm 1.66^{\mathrm{a}}$ \\
1.5 & 2.0 & 1.0 & $693.21 \pm 3.58^{\mathrm{d}}$ & $88.00 \pm 0.94^{\mathrm{b}}$ \\
1.5 & 2.0 & 2.0 & $708.55 \pm 5.32^{\mathrm{c}}$ & $90.19 \pm 2.46^{\mathrm{b}}$ \\
1.5 & 2.0 & 3.0 & $735.69 \pm$ & $94.58 \pm 1.39^{\mathrm{a}}$ \\
1.5 & 2.0 & 4.0 & $749.37 \pm 13.26^{\mathrm{a}}$ & $93.82 \pm 2.61^{\mathrm{a}}$ \\
1.5 & 2.0 & 5.0 & $721.63 \pm 14.92^{\mathrm{b}}$ & $89.57 \pm 1.78^{\mathrm{b}}$ \\
\hline
\end{tabular}

* Data are expressed as mean \pm standard deviation (SD) followed by different superscript letters

(a-d) within the same column are significantly different at $\mathrm{p} \leq 0.05$.

In this part of the optimization, $0 \%$ (w/v) GOS was served as a control. The GOS concentration had a significant effect $(\mathrm{p} \leq 0.05)$ on bead size. The diameter of beads increased significantly when the concentration of GOS increased from $1.0 \%(\mathrm{w} / \mathrm{v})$ to $4.0 \%(\mathrm{w} / \mathrm{v})$. Besides, B. lactis beads without GOS was smaller than the size of the bead with GOS. This result is aligned with Siang et al. (2019) who reported that the addition of prebiotic isomalto-oligosaccharide to alginate beads coated with poly-L-lysine would produce larger microbeads. Furthermore, Krasaekoopt \& Watcharapoka (2014) also observed that the addition of inulin or GOS to $L$ acidophilus and L. casei significantly $(\mathrm{p} \leq 0.05)$ increased the bead size. However, the study also reported that the increase in prebiotic concentration had no impact on the size of the beads, which was in contrast with the findings of this study. This could be due to the smaller range of prebiotic concentration was used $(0.5-1.5 \%$ $\mathrm{w} / \mathrm{v})$ in the study as compared to this study $(1.0-5.0 \% \mathrm{w} / \mathrm{v})$. The increase in the diameter size as GOS concentration increases could be due to the increase in the mass of the microbeads. However, there was a decrease in beads diameter when GOS concentration increased from $4 \%(\mathrm{w} / \mathrm{v})$ to $5 \%(\mathrm{w} / \mathrm{v})$. This could be due to the similar drying issue as mentioned previously, where the drying of the microbeads was not controlled, hence resulted in an inconsistency in the diameter of the beads (Smrdel et al., 2008). Figure 1 shows the shape and morphology of the encapsulated $B$. lactis $\mathrm{Bi}-07$ with different concentration of GOS.
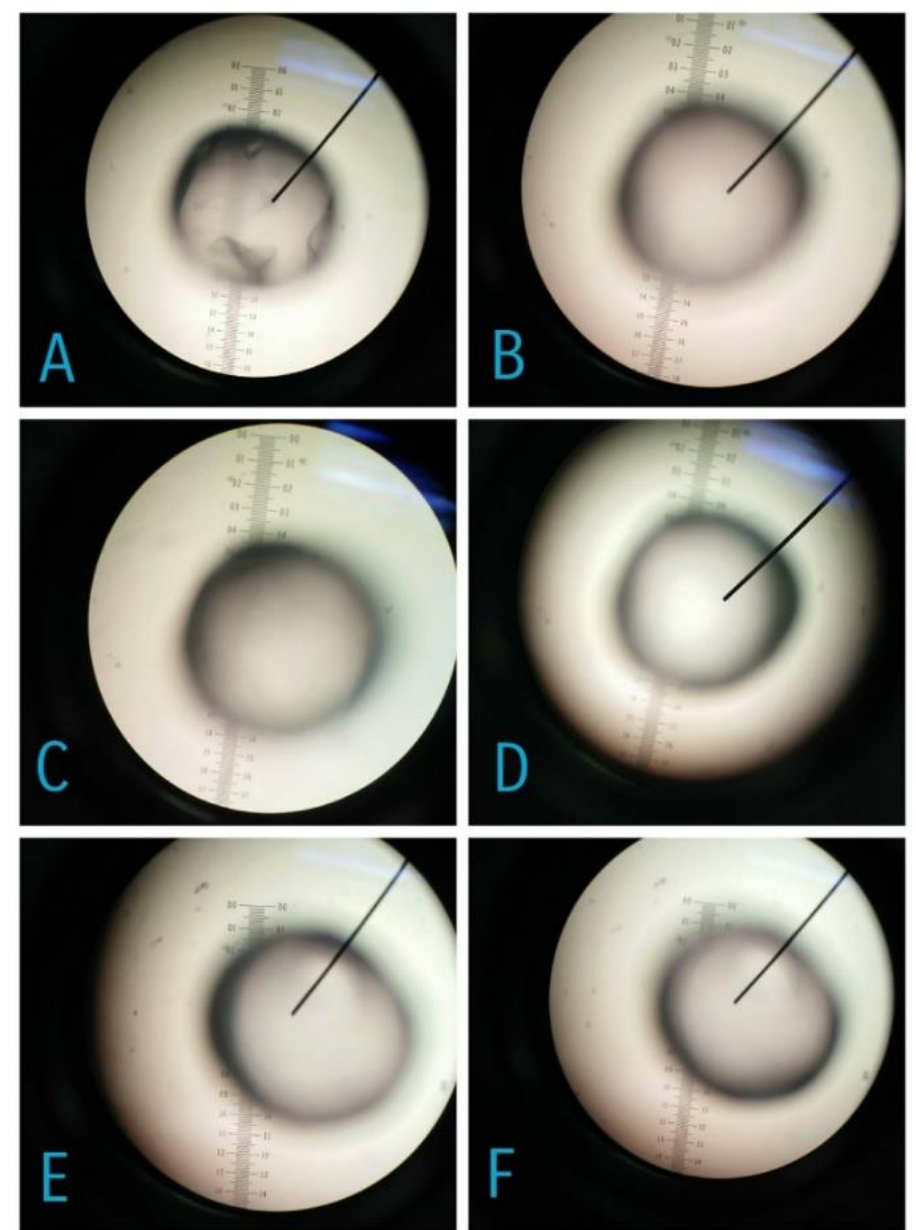

Figure 1 Shape and morphology of encapsulated B. lactis Bi-07 (A-F) with different concentration of GOS (A: $0 \% \mathrm{w} / \mathrm{v} ; \mathrm{B}: 1 \% \mathrm{w} / \mathrm{v} ; \mathrm{C}: 2 \% \mathrm{w} / \mathrm{v} ; \mathrm{D}: 3 \% \mathrm{w} / \mathrm{v}$, E: $4 \% \mathrm{w} / \mathrm{v} ; \mathrm{F}: 5 \% \mathrm{w} / \mathrm{v})$

Table 2 also shows that GOS concentration at $0 \%(\mathrm{w} / \mathrm{v})$ displayed the highest MEE of $96.28 \%$. A similar result was reported by (Krasaekoopt \& Watcharapoka, 2014) for $L$. case $i$ where the encapsulation yield was highest for the $L$. casei beads without prebiotic. This result could be explained by the absent of prebiotic in the beads allowed higher loading of the probiotic $B$. lactis, hence resulting in higher MEE. On the other hand, the microencapsulation efficiency increased significantly $(\mathrm{p} \leq 0.05)$ when the GOS concentration increased from $1 \%(\mathrm{w} / \mathrm{v})$ to $3 \%(\mathrm{w} / \mathrm{v})$ Besides, the addition of $3 \%(\mathrm{w} / \mathrm{v})$ GOS to the $B$. lactis microbeads yielded the highest MEE of $94.58 \%$ among the microbeads with GOS. This showed that $3 \%$ (w/v) GOS was the optimum amount to protect and promote $B$. lactis growth in the microbeads. However, the further increase of GOS concentration to $5 \%(\mathrm{w} / \mathrm{v}) \mathrm{had}$ caused a significant decrease in MEE. Similar results were found by $\mathrm{Ng}$ et al . (2019), Yee et al. (2019), and Yong et al. (2020) where the microencapsulation efficiency was not directly proportional to the prebiotic concentration. Furthermore, both Yee et al. (2019) and Yong et al. (2020) also reported that the optimum prebiotic concentration was also $3 \%(\mathrm{w} / \mathrm{v})$ for probiotic microbeads produced from co-extrusion technique, which was in line with the findings of this study. This could be due to the high amount of prebiotic had caused an increase in the mass of the microbeads, thus reducing the encapsulated probiotic in the microbeads (Krasaekoopt \& Watcharapoka, 2014). Besides, Ann et al. (2007) also suggested that overloading of prebiotic may cause collision and abrasion between probiotic and wall materials during encapsulation, resulting in lower MEE. Furthermore, the time taken for probiotic to utilize GOS for growth during microencapsulation process might be too short. As 3.0\% (w/v) GOS gave the highest MEE in the second part of the optimization, the concentration was chosen and fixed for further analysis.

Morphology, size and microencapsulation efficiency of the optimized $B$. lactis microbeads

The optimized B. lactis $\mathrm{Bi}-07$ microbeads were produced using $1.5 \%(\mathrm{w} / \mathrm{v})$ sodium alginate, $2.0 \%(\mathrm{w} / \mathrm{v})$ calcium chloride, and $3.0 \%(\mathrm{w} / \mathrm{v})$ GOS based on the optimization findings. Figure 2 displayed the shape and size of the optimized $B$. 
lactis $\mathrm{Bi}-07$ microbeads; while the microencapsulation efficiency and average diameter of the B. lactis microbeads without and with GOS are shown in Table 3 .

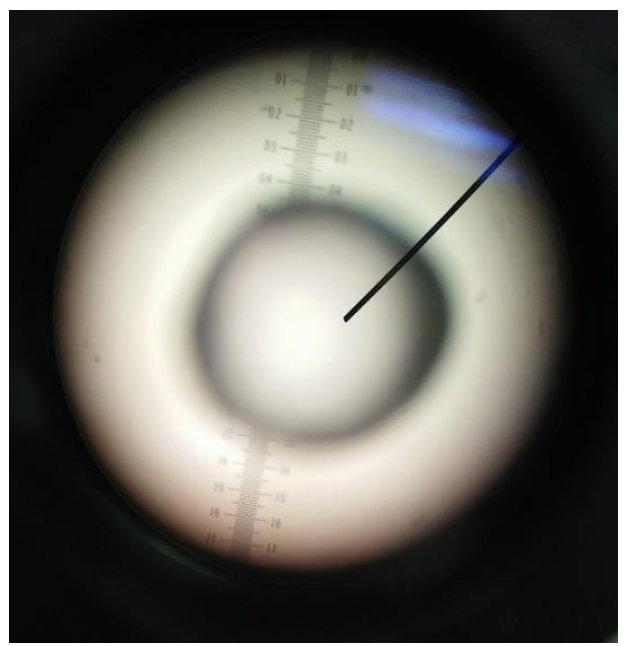

Figure 2 Shape and size of encapsulated B. lactis $\mathrm{Bi}-07$

Table 3 Microencapsulation efficiency and average bead size of alginate-chitosan beads with or without GOS

\begin{tabular}{lcc}
\hline Parameter & Without GOS & With GOS \\
\hline Diameter of beads $(\mu \mathrm{m})$ & $725.56 \pm 9.84^{\mathrm{b}}$ & $763.91 \pm 13.27^{\mathrm{a}}$ \\
$\begin{array}{l}\text { Microencapsulation efficiency } \\
(\%)\end{array}$ & $95.14 \pm 1.67^{\mathrm{a}}$ & $92.38 \pm 1.52^{\mathrm{b}}$ \\
\hline
\end{tabular}

*Data are expressed as mean \pm standard deviation (SD) followed by different superscript letter (a-b) within the same row are significantly different at $\mathrm{p} \leq 0.05$

In Figure 2, the B. lactis $\mathrm{Bi}-07$ microbeads appeared to be white in colour and surrounded by a thin layer of the membrane. The microbead was spherical in shape with a smooth and uniform bead surface under an optical microscope. The smooth surface of the microbeads are crucial as beads with a broken surface can result in lower survivability of the encapsulated cells (Yee $\boldsymbol{e t}$ al., 2019). However, few of the microbeads were found to be an irregular and oval shape. This might be due to the dispersion of the probiotics in the microbeads was not uniform and the leakage from the outer orifice that caused the beads to clump together. Besides, Lotfipour et al. (2012) also observed that the viscosity of sodium alginate can also affect the shape of microbeads. Nevertheless, most of the microbeads produced were spherical and uniform in shape throughout the microencapsulation process. In terms of microencapsulation efficiency, the encapsulated B. lactis $\mathrm{Bi}-07$ without GOS had a significantly higher MEE $(\mathrm{p} \leq 0.05)$ as compared to the encapsulated B. lactis Bi-07 without GOS. The result is in agreement with Gandomi et al. (2016) and Krasaekoopt \& Watcharapoka (2014) who reported that the addition of prebiotic resulted in lower probiotic cell count in the microbeads, hence reducing in microencapsulation efficiency. Besides, Silva et al. (2018) also highlighted that the prebiotic sources may not have time to act as a substrate for probiotic at this step of the process yet, hence did not contribute to the microencapsulation efficiency.

Furthermore, the addition of GOS had a significant effect $(\mathrm{p} \leq 0.05)$ on bead size The microbead with GOS was significantly $(\mathrm{p} \leq 0.05)$ larger than the microbead without GOS. This finding is consistent with the result reported in the optimization of GOS in this study, Krasaekoopt \& Watcharapoka (2014) and Chávarri et al. (2010). Chávarri et al. (2010) reported that the average microbead size of chitosan-coated beads with quercetin was significantly larger $(542.74 \mu \mathrm{m})$ than beads without the addition of quercetin $(523.09 \mu \mathrm{m})$. This could be due to the increase in mass when the GOS is incorporated into the microbeads.

From Table 3, the average bead size was $725.56 \mu \mathrm{m}$ and $763.91 \mu \mathrm{m}$ in beads encapsulated without and with GOS, respectively. The result was similar with the findings reported by Piazza \& Roversi (2011) and Silva et al. (2018) who produced microbeads with the size ranged between $700 \mu \mathrm{m}$ and $800 \mu \mathrm{m}$ using the co-extrusion technique. In contrast, Yee et al. (2019) and Shinde et al. (2014) who produced alginate microbeads with prebiotic using the co-extrusion technique reported smaller size of microbeads ranged between $543-670 \mu \mathrm{m}$ and $423-486$ $\mu \mathrm{m}$, respectively. The difference in bead size could be due to the viscosity of alginate, the distance between the nozzle and calcium chloride, and the size of nozzle used (Klokk \& Melvik, 2002; Solanki et al., 2013).

The production of micron-sized bead is able to give food product a smoother texture as compared to millimetre-sized bead (Krasaekoopt $\boldsymbol{e t}$ al., 2004). Beads with a diameter of $3 \mu \mathrm{m}$ are barely detectable in mouth, however larger beads with a diameter of $1000 \mu \mathrm{m}$ give a coarse texture in terms of mouthfeel (Nag et al., 2011). Nevertheless, in order to provide sufficient protection to probiotics in the gastrointestinal environment, Hansen et al. (2002) suggested that a minimum diameter of $100 \mu \mathrm{m}$ is still needed to ensure the probiotics survive through the gastrointestinal tract. Moreover, the selection of a suitable encapsulation technique and wall material formulation can encapsulate most of the probiotic cells within the microbeads and results in high microencapsulation efficiency (Shinde $\boldsymbol{e t}$ al. 2014). Despite the lower MEE caused by the addition of prebiotic, optimized encapsulated B. lactis with GOS was still able to achieve at least $92.0 \%$ of the MEE. This indicates that there was barely any loss of probiotic cell count during the microencapsulation process. Hence, this shows that the co-extrusion technique and the optimized formulation for microencapsulation were suitable for the encapsulation of B. lactis $\mathrm{Bi}-07$.

Viability of free cells, encapsulated Bifidobacterium lactis Bi-07 with and without GOS under simulated gastric juice (SGJ)

Sequential digestion is defined as continuous incubation of bacteria in the gastrointestinal environment. Probiotic bacteria tend to lose its viability when exposed to an adverse condition such as the exposure to oxygen, heat and the presence of pepsin and bile salt in the gastrointestinal tract (Saarela et al., 2005) One of the main purposes of probiotic microencapsulation is to allow them to survive and remain high viability $\left(\geq 10^{7} \mathrm{CFU} / \mathrm{mL}\right)$ throughout the gastrointestinal transition (Nazzaro et al., 2009). In this study, the viability of the encapsulated $B$ lactis $\mathrm{Bi}-07$ with GOS, without GOS and free cells under simulated gastric condition ( $\mathrm{pH} 2.0$ for 2 hours) were evaluated and shown in Figure 3.

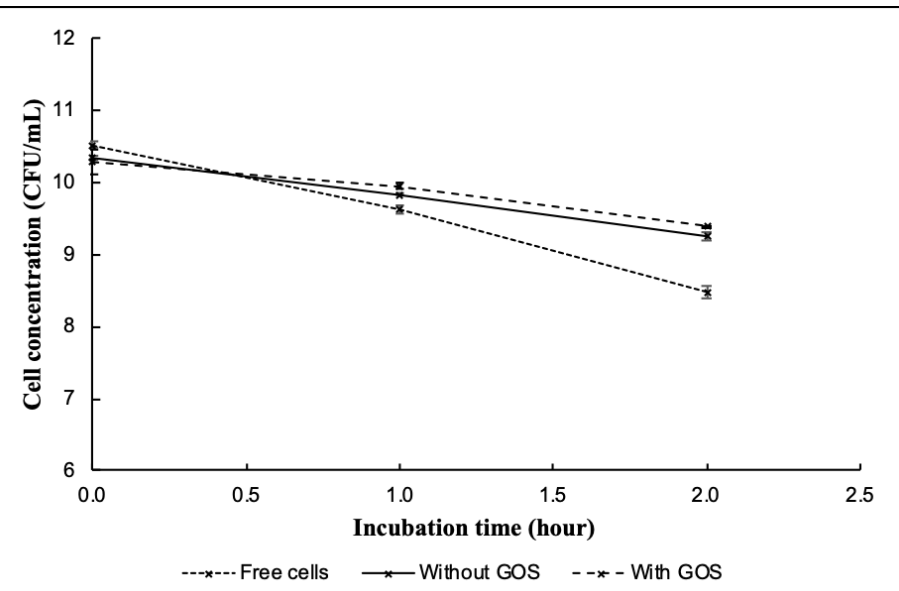

Figure 3 Total viable cell count (log $\mathrm{CFU} / \mathrm{mL}$ ) of free, encapsulated $B$. lactis $\mathrm{Bi}$ 07 with and without GOS in simulated gastric juice ( $\mathrm{pH} 2.0)$ during incubation at $37^{\circ} \mathrm{C}$ for 2 hours

Figure 3 demonstrated that the viability of free cells, microencapsulated $B$. lactis Bi-07 with and without GOS showed significant decreased $(\mathrm{p} \leq 0.05)$ after subjected to 2 hours of incubation in SGJ solution. However, free cells displayed a higher rate of decrease as compared to the encapsulated B. lactis Bi-07 with and without GOS after 2 hours of incubation in SGJ solution. The viable cell count of free cells had a significant decline $(\mathrm{p} \leq 0.05)$ at both 1 and 2 hours of incubation. The viability of free cells decreased by $19.5 \%$ from $10.52 \log$ CFU/mL to $9.63 \mathrm{log}$ $\mathrm{CFU} / \mathrm{mL}$ after 60 minutes, and further decreased to $8.47 \mathrm{log}$ CFU/mL after 120 minutes of incubation. Gandomi et al. (2016) showed similar findings where free cells displayed a more drastic decreased after incubated in SGJ solution as compared to encapsulated probiotic. The decline was expected as most of the probiotic cells are sensitive to low $\mathrm{pH}$ conditions. This is supported by Mustafa $\boldsymbol{e t}$ al. (2016) who highlighted that the absence of protection for free cells may lead to a great loss of cell viability when exposed to the acidic environment.

On the other hand, the viability of encapsulated B. lactis Bi-07 without GOS showed no significant decreased $(p>0.05)$ after 60 minutes of incubation in SGJ solution. However, after 120 minutes of incubation in SGJ solution, the encapsulated $B$. lactis Bi-07 without GOS displayed significant decreased ( $\mathrm{p} \leq$ 0.05 ) of $10.5 \%$ from $10.34 \log \mathrm{CFU} / \mathrm{mL}(0 \mathrm{~h})$ to $9.25 \log \mathrm{CFU} / \mathrm{mL}(2 \mathrm{~h})$. Despite the significant decreased after 120 minutes of incubation, the wall/coating materials and co-extrusion technique were still able to protect $B$. lactis under acidic/ gastric condition as it displayed lower reduction compared to free cells. Chitosan is a suitable polymer to form a gel with sodium alginate by ionic crosslinking (Lucinda-Silva et al., 2010; Shori, 2017). Various studies have reported that alginate microbeads coated with chitosan had a significant effect on the stability of the alginate beads, hence enhancing the survival rate of encapsulated probiotics. Yu et al. (2001) claimed that the use of alginate-chitosan for the encapsulation of Bifidobacterium spp. had higher survivability under the acidic condition as compared to the probiotic encapsulation without chitosan. In addition, the high survival rate of microencapsulated probiotics cells was in agreement with Chávarri et al. (2010) who reported that the alginate-chitosan capsules had enhanced the survival rate of Lactobacillus gasseri and Bifidobacterium bifidum $\left(10^{7} \mathrm{CFU} / \mathrm{mL}\right)$ as compared to free cells after 2 hours incubation in SGJ.

Similar to the encapsulated B. lactis without GOS, the viable cell count of encapsulated $B$. lactis $\mathrm{Bi}-07$ with GOS showed no significant difference between 0 hour and 1 hour incubation in SGJ. However, after 120 minutes of incubation in 
SGJ solution, the viable cell count of encapsulated B. lactis Bi-07 with GOS dropped $8.66 \%(\mathrm{p} \leq 0.05)$ from $10.28 \log \mathrm{CFU} / \mathrm{mL}(0 \mathrm{~h})$ to $9.39 \log \mathrm{CFU} / \mathrm{mL}(2$ h). Even though the encapsulated B. lactis with GOS showed a lower reduction than the encapsulated $B$. lactis without GOS, the presence of GOS did not significantly improve the survivability of $B$. lactis Bi-07 in acidic SGJ solution. This result concurs with Sultana et al. (2000) who reported that the encapsulated L. acidophilus and Bifidobacterium spp. with Hi-Maize (prebiotic) did not significantly improve the survival rate under gastric condition.

After 2 hours of incubation in SGJ solution, the viability of free cells was significantly lower than microencapsulated B. lactis Bi-07 with and without GOS While the viable cell count of encapsulated B. lactis Bi-07 with GOS was slightly higher than encapsulated $B$. lactis Bi-07 without GOS. Overall, free cells, microencapsulated $B$. lactis $\mathrm{Bi}-07$ with and without GOS were able to survive 2 hours in acidic gastric condition with a viable cell count of more than $10^{8} \mathrm{CFU} / \mathrm{mL}$.

\section{Viability of free cells, encapsulated Bifidobacterium lactis $\mathrm{Bi}-07$ without and with GOS under simulated intestinal juice (SIJ)}

A good probiotic must be able to survive in both highly acidic gastric conditions and highly alkaline intestinal condition. Prior to reaching the large intestines, probiotics have to pass through the small intestine which contains a high concentration of bile salt (Cook et al., 2012). The growth of probiotics could be inhibited by the bile salts present in the small intestine. Thus, wall material and prebiotic selection in microencapsulation of probiotics are important criteria to ensure enough protection to probiotics (Annan et al., 2008). After 2 hours of incubation in SGJ, the beads were transferred to SIJ solution and incubated for 5 hours. The total viable cell count of free, encapsulated B. lactis Bi-07 (with and without GOS) when exposed to SIJ for 5 hours are shown in Figure 4.

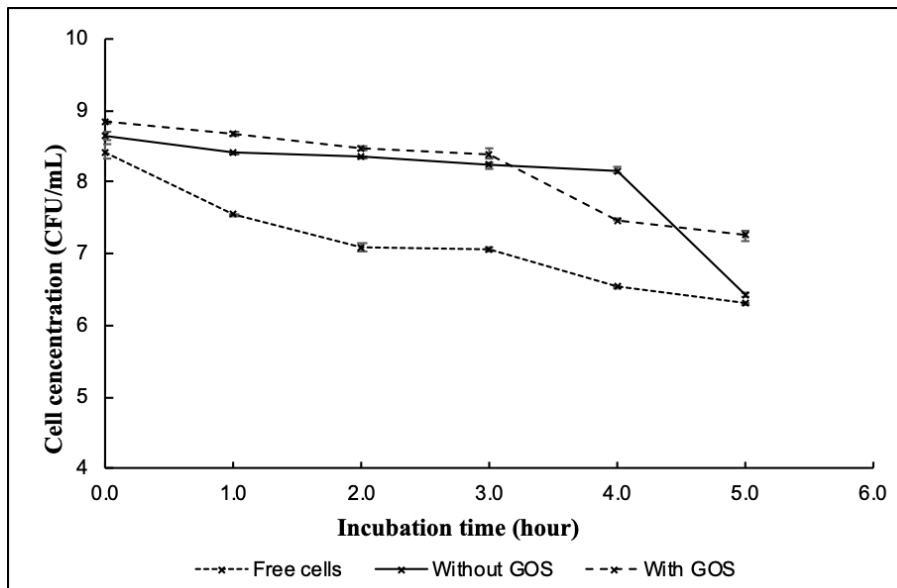

Figure 4 Total viable cell count (log $\mathrm{CFU} / \mathrm{mL})$ of free, encapsulated $B$. lactis Bi07 with and without GOS in simulated intestinal juice ( $\mathrm{pH} 7.5)$ during incubation at $37^{\circ} \mathrm{C}$ for 5 hours

As seen in Figure 4, the viability of free, encapsulated B. lactis $\mathrm{Bi}-07$ without and with GOS significantly decreased after 5 hours of incubation in SIJ. Free cells showed an initial significant reduction of viable cell count from $8.43 \log$ CFU/mL to $7.54 \log \mathrm{CFU} / \mathrm{mL}$ after one hour of exposure to SIJ solution. The viable cells dropped continuously to $6.31 \log \mathrm{CFU} / \mathrm{mL}$ after 5 hours incubation in SIJ. The percentage loss was about $25 \%$ with only $10^{6} \mathrm{CFU} / \mathrm{mL}$ of viable cells survived after the SIJ incubation. Results obtained in this study can be supported by Annan et al. (2008) and Ng et al. (2019) who reported that the viable cell count of free cells Bifidobacterium adolescentis $15703 \mathrm{~T}$ and L. plantarum 299v dropped to about $6 \log \mathrm{CFU} / \mathrm{mL}$ after 4 - 5 hours of incubation in SIJ. The viability reduction of free cells B. lactis $\mathrm{Bi}-07$ in SIJ showed that the probiotic is susceptible to alkaline condition and bile salt. Lai et al. (2020) suggested that bile salts could exert toxicity effect on the probiotic's cell membrane, which could lead to cell death.

On the other hand, the viable cells count of encapsulated B. lactis Bi-07 without GOS showed no significant difference from 0 hour to 4 hours of incubation in SIJ However, the viable cell count dropped drastically from $8.17 \log \mathrm{CFU} / \mathrm{mL}$ to 6.43 $\log \mathrm{CFU} / \mathrm{mL}$ at the last hour of SIJ incubation. The percentage of viability loss was $25.7 \%$ with a final cell count of $10^{6} \mathrm{CFU} / \mathrm{mL}$. Similar results were reported by Kumherová et al. (2020) where the viability of B. lactis BB12 alginate microbeads reduced from $8 \log \mathrm{CFU} / \mathrm{mL}$ to $6 \log \mathrm{CFU} / \mathrm{mL}$ after 4 hours of incubation. The drastic reduction of $B$. lactis viable cell count at the last hour of SIJ incubation demonstrated that the wall material, sodium alginate may be susceptible towards the alkaline condition and degraded after 5 hours of incubation in SIJ solution. According to Annan et al. (2008), alginate is stable under low pH solution, but it is unstable in weak basic conditions, thus the encapsulated probiotic cells had a higher reduction in viable cell count within intestinal transition than gastric condition.
Meanwhile, the viable cell count of encapsulated B. lactis Bi-07 with GOS also showed significantly decreased after 5 hours of incubation in SIJ. In contrast with the encapsulated $B$. lactis $\mathrm{Bi}-07$ without GOS, the viable cell count of encapsulated B. lactis $\mathrm{Bi}-07$ with GOS dropped steadily from $8.84 \log \mathrm{CFU} / \mathrm{mL}$ to $7.25 \mathrm{log}$ $\mathrm{CFU} / \mathrm{mL}$ after 5 hours of SIJ incubation. This concurs with the results reported by Ng et al. (2019) where $7 \log$ CFU/mL of encapsulated L. plantarum with prebiotic fructooligosaccharides was found after 5 hours of SIJ incubation. Although there was a reduction in viability at the first 4 hours of incubation for encapsulated $B$ lactis $\mathrm{Bi}-07$ with GOS, the total reduction was lower than encapsulated $B$. lactis Bi-07 without GOS with $18 \%$ of viability reduction. This proves that the addition of GOS in the probiotic microencapsulation had improved the survivability of probiotic in SIJ condition. This is consistent with the findings by Darjani et al. (2016) where encapsulated $L$. case $i$ with prebiotic showed a lesser reduction than encapsulated $L$. case $i$ without prebiotic and free cells. Furthermore, Krasaekoopt \& Watcharapoka (2014) also reported that both encapsulated L. acidophilus and L. casei with prebiotic (GOS or inulin) displayed lower reduction than encapsulated probiotics without prebiotic after 3 hours of SIJ incubation. The presence of prebiotic (GOS) in the microbeads could help probiotic to survive through harsh condition by acting as the nutrient source for the probiotic. According to Ann et al. (2007), probiotics could utilize prebiotic as a carbon source for growth, hence increasing viability in the microbeads throughout gastrointestinal transit. Furthermore, prebiotic could protect probiotic by forming stronger network through chemical bonds with the wall material (Silva $\boldsymbol{e t}$ al. 2018a). Hence, GOS could also act as a protective agent towards B. lactis throughout the intestinal incubation, which leads to higher total viable cell count than encapsulated B. lactis without GOS.

Overall, after the sequential digestion (SGJ for 2 hours and SIJ for 5 hours), $B$. lactis free cells had a $40.0 \%$ reduction, followed by encapsulated $B$. lactis withou GOS with a $37.8 \%$ reduction. The encapsulated B. lactis with GOS demonstrated the least reduction of $29.5 \%$ after the sequential digestion. Besides, both free cells and encapsulated $B$. lactis without GOS have about $10^{6} \mathrm{CFU} / \mathrm{mL}$; while the encapsulated $B$. lactis with GOS remained $10^{7} \log \mathrm{CFU} / \mathrm{mL}$ at the end of the sequential digestion. Although free cells and encapsulated B. lactis $\mathrm{Bi}-07$ without GOS met the desired requirement of probiotic concentration, a higher amount of probiotic cell count is still recommended to ensure sufficient amount of probiotics survive through prolonged storage before consumption. Besides, the higher amount of viable cell count demonstrated by the encapsulated B. lactis Bi-07 with GOS allows it to be incorporated into food or beverage products as a functional food ingredient.

\section{CONCLUSION}

In this work, microencapsulation of B. lactis Bi-07 was successfully optimized with microencapsulation efficiency of more than $94 \%$. This indicates that there was no significant loss of $B$. lactis $\mathrm{Bi}-07$ during microencapsulation. The encapsulated $B$. lactis $\mathrm{Bi}-07$ with GOS displayed higher cell viability (> 107 $\mathrm{CFU} / \mathrm{mL}$ ) than encapsulated $B$. lactis $\mathrm{Bi}-07$ without GOS and free cells after the simulated gastrointestinal treatment. This showed that the optimized encapsulated B. lactis $\mathrm{Bi}-07$ with GOS could survive the human gastrointestinal to confer health benefits to the host and the potential to be incorporated into functional foods Future studies could incorporate the optimized encapsulated B. lactis $\mathrm{Bi}-07$ with GOS into different food matrices to evaluate its survivability under different conditions and prolonged storage. Besides, future studies could also further improve on the drying of the microbeads by using freeze drying to prevent the inconsistent of bead size.

Acknowledgments: The project was supported by UCSI University Pioneer Scientist Incentive Fund (PSIF) grant (Proj-In-FAS-055).

\section{REFERENCES}

Afzaal, M., Khan, A. U., Saeed, F., Ahmed, A., Ahmad, M. H., Maan, A. A., Tufail, T., Anjum, F. M., \& Hussain, S. (2019). Functional exploration of free and encapsulated probiotic bacteria in yogurt and simulated gastrointestinal conditions. Food Science and Nutrition, 7(12), 3931-3940. https://doi.org/10.1002/fsn3.1254 Ann, E. Y., Kim, Y., Oh, S., Imm, J. Y., Park, D. J., Han, K. S., \& Kim, S. H. (2007). Microencapsulation of Lactobacillus acidophilus ATCC 43121 with prebiotic substrates using a hybridisation system. International Journal of Food Science and Technology, 42(4), 411-419. https://doi.org/10.1111/j.13652621.2007.01236.x

Annan, N. T., Borza, A. D., \& Hansen, L. T. (2008). Encapsulation in alginatecoated gelatin microspheres improves survival of the probiotic Bifidobacterium adolescentis $15703 \mathrm{~T}$ during exposure to simulated gastro-intestinal conditions Food Research International, 41(2), 184-193. https://doi.org/10.1016/j.foodres.2007.11.001

Bepeyeva, A., de Barros, J. M. S., Albadran, H., Kakimov, A. K., Kakimova, Z. K., Charalampopoulos, D., \& Khutoryanskiy, V. V. (2017). Encapsulation of Lactobacillus casei into calcium pectinate-chitosan beads for enteric delivery. Journal of Food Science, 82(12), 2954-2959. https://doi.org/10.1111/1750 $\underline{3841.13974}$ 
Burgain, J., Gaiani, C., Linder, M., \& Scher, J. (2011). Encapsulation of probiotic living cells: From laboratory scale to industrial applications. Journal of Food Engineering, 104(4), 467-483. https://doi.org/10.1016/j.jfoodeng.2010.12.031 Cao, N., Chen, X. B., \& Schreyer, D. J. (2012). Influence of calcium ions on cell survival and proliferation in the context of an alginate hydrogel. ISRN Chemical Engineering, 2012, 1-9. https://doi.org/10.5402/2012/516461

Chan, L. Y., \& Pui, L. P. (2020). Microencapsualtion of Lactobacillus acidophilus 5 with isomalto-oligosaccharides. Carpathian Journal of Food Science and Technology, 12(2), 26-36. https://doi.org/10.34302/crpjfst/2020.12.2.3

Chávarri, M., Marañón, I., Ares, R., Ibáñez, F. C., Marzo, F., \& Villarán, M. del C. (2010). Microencapsulation of a probiotic and prebiotic in alginate-chitosan capsules improves survival in simulated gastro-intestinal conditions. International Journal of Food Microbiology, 142(1-2), 185-189. https://doi.org/10.1016/j.ijfoodmicro.2010.06.022

Chew, S. C., Tan, C. P., Long, K., \& Nyam, K. L. (2015). In-vitro evaluation of kenaf seed oil in chitosan coated-high methoxyl pectin-alginate microcapsules. Industrial Crops and Products, 76, 230-236. https://doi.org/10.1016/j.indcrop.2015.06.055

Chia, P. X., Tan, L. J., Huang, C. M. Y., Chan, E. W. C., \& Wong, S. Y. W. (2015) Hydrogel beads from sugar cane bagasse and palm kernel cake, and the viability of encapsulated Lactobacillus acidophilus. E-Polymers, 15(6), 411-418 https://doi.org/10.1515/epoly-2015-0133

Cook, M. T., Tzortzis, G., Charalampopoulos, D., \& Khutoryanskiy, V. V. (2012). Microencapsulation of probiotics for gastrointestinal delivery. Journal of Controlled Release, 162(1), 56-67. https://doi.org/10.1016/i.jconrel.2012.06.003 Darjani, P., Hosseini Nezhad, M., Kadkhodaee, R., \& Milani, E. (2016). Influence of prebiotic and coating materials on morphology and survival of a probiotic strain of Lactobacillus casei exposed to simulated gastrointestinal conditions. LWT Food Science and Technology, 73, 162-167. https://doi.org/10.1016/j.lwt.2016.05.032

Etchepare, M. de A., Barin, J. S., Cichoski, A. J., Jacob-Lopes, E., Wagner, R., Fries, L. L. M., \& Menezes, C. R. de. (2015). Microencapsulation of probiotics using sodium alginate. Ciência Rural, 45(7), 1319-1326. https://doi.org/10.1590/0103-8478cr20140938

Favretto, D. C., Pontin, B., \& Moreira, T. R. (2013). Effect of the consumption of a cheese enriched with probiotic organisms (Bifidobacterium lactis Bi-07) in improving symptoms of constipation. Arquivos de Gastroenterologia, 50(3), 196201. https://doi.org/10.1590/S0004-28032013000200035

Gandomi, H., Abbaszadeh, S., Misaghi, A., Bokaie, S., \& Noori, N. (2016). Effect of chitosan-alginate encapsulation with inulin on survival of Lactobacillus rhamnosus GG during apple juice storage and under simulated gastrointestinal conditions. LWT - Food Science and Technology, 69, 365-371. https://doi.org/10.1016/i.lwt.2016.01.064

Goh, C. H., Heng, P. W. S., \& Chan, L. W. (2012). Alginates as a useful natura polymer for microencapsulation and therapeutic applications. Carbohydrate Polymers, 88(1), 1-12. https://doi.org/10.1016/j.carbpol.2011.11.012

Goulas, T., Goulas, A., Tzortzis, G., \& Gibson, G. R. (2009). Expression of four $\beta$-galactosidases from Bifidobacterium bifidum NCIMB41171 and their contribution on the hydrolysis and synthesis of galactooligosaccharides. Applied Microbiology and Biotechnology, 84(5), 899-907. https://doi.org/10.1007/s00253009-2009-5

Hansen, L. T., Allan-Wojtas, P. M., Jin, Y. L., \& Paulson, A. T. (2002). Surviva of Ca-alginate microencapsulated Bifidobacterium spp. in milk and simulated gastrointestinal conditions. Food Microbiology, 19(1), 35-45. https://doi.org/10.1006/fmic.2001.0452

Hinz, S. W. A., Van Den Broek, L. A. M., Beldman, G., Vincken, J. P., \& Voragen, A. G. J. (2004). $\beta$-Galactosidase from Bifidobacterium adolescentis DSM20083 prefers $\beta(1,4)$-galactosides over lactose. Applied Microbiology and Biotechnology, 66(3), 276-284. https://doi.org/10.1007/s00253-004-1745-9

Hong, K. B., Kim, J. H., Kwon, H. K., Han, S. H., Park, Y., \& Suh, H. J. (2016) Evaluation of prebiotic effects of high-purity galactooligosaccharides in vitro and in vivo. Food Technology and Biotechnology, 54(2), 156-163. https://doi.org/10.17113/ftb.54.02.16.4292

Hung, M. N., \& Lee, B. (2002). Purification and characterization of a recombinan $\beta$-galactosidase with transgalactosylation activity from Bifidobacterium infantis HL96. Applied Microbiology and Biotechnology, 58(4), 439-445. https://doi.org/10.1007/s00253-001-0911-6

Klokk, T. I., \& Melvik, J. E. (2002). Controlling the size of alginate gel beads by use of a high electrostatic potential. Journal of Microencapsulation, 19(4), 415 424. https://doi.org/10.1080/02652040210144234

Krasaekoopt, W., Bhandari, B., \& Deeth, H. (2004). The influence of coating materials on some properties of alginate beads and survivability of microencapsulated probiotic bacteria. International Dairy Journal, 14(8), 737 743. https://doi.org/10.1016/j.idairyj.2004.01.004

Krasaekoopt, W., \& Watcharapoka, S. (2014). Effect of addition of inulin and galactooligosaccharide on the survival of microencapsulated probiotics in alginate beads coated with chitosan in simulated digestive system, yogurt and fruit juice. LWT - Food Science and Technology, 57(2), 761-766 https://doi.org/10.1016/j.lwt.2014.01.037

Kumherová, M., Veselá, K., Jokešová, K., Klojdová, I., \& Horáčková, Š. (2020).
Influence of co-encapsulation of Bifidobacterium animalis subsp. lactis Bb12 with inulin and ascorbic acid on its viability. Czech Journal of Food Sciences, 38(1), 57-62. https://doi.org/10.17221/292/2019-cjfs

Lai, J. T., Lai, K. W., Zhu, L. Y., Nyam, K. L., \& Pui, L. P. (2020) Microencapsulation of Lactobacillus plantarum 299v and its storage in kuini juice. Malaysian Journal of Microbiology, 16(4), 235-244 https://doi.org/10.21161/mjm.190398

Lotfipour, F., Mirzaeei, S., \& Maghsoodi, M. (2012). Evaluation of the effect of $\mathrm{CaCl} 2$ and alginate concentrations and hardening time on the characteristics of Lactobacillus acidophilus loaded alginate beads using response surface analysis. Advanced Pharmaceutical Bulletin, 2(1), 71-78 https://doi.org/10.5681/apb.2012.010

Lucinda-Silva, R. M., Salgado, H. R. N., \& Evangelista, R. C. (2010). Alginatechitosan systems: In vitro controlled release of triamcinolone and in vivo gastrointestinal transit. Carbohydrate Polymers, 81(2), 260-268. https://doi.org/10.1016/j.carbpol.2010.02.016

Lyra, A., Saarinen, M., Putaala, H., Olli, K., Lahtinen, S. J., Ouwehand, A. C., Madetoja, M., \& Tiihonen, K. (2012). Bifidobacterium animalis ssp. lactis 420 protects against indomethacin-induced gastric permeability in rats. Gastroenterology Research and Practice, 2012, 1-9. https://doi.org/10.1155/2012/615051

Maneerat, S., Lehtinen, M. J., Childs, C. E., Forssten, S. D., Alhoniemi, E., Tiphaine, M., Yaqoob, P., Ouwehand, A. C., \& Rastall, R. A. (2013). Consumption of Bifidobacterium lactis $\mathrm{Bi}-07$ by healthy elderly adults enhances phagocytic activity of monocytes and granulocytes. Journal of Nutritional Science, 2, 1-10. https://doi.org/10.1017/jns.2013.31

Morovic, W., Roper, J. M., Smith, A. B., Mukerji, P., Stahl, B., Rae, J. C., \& Ouwehand, A. C. (2017). Safety evaluation of HOWARU® Restore (Lactobacillus acidophilus NCFM, Lactobacillus paracasei Lpc-37, Bifidobacterium animalis subsp. lactis $\mathrm{Bl}-04$ and $B$. lactis $\mathrm{Bi}-07$ ) for antibiotic resistance, genomic risk factors, and acute toxicity. Food and Chemical Toxicology, 110(October), 316324. https://doi.org/10.1016/j.fct.2017.10.037

Mustafa, S. M., Chua, L. S., El- Enshasy, H. A., Majid, F. A. A., \& Malek, R. A. (2016). A review on fruit juice probiotication: Pomegranate. Current Nutrition \& Food Science, 12(1), 4-11. https://doi.org/10.2174/1573401311666151015213508 Nag, A., Han, K. S., \& Singh, H. (2011). Microencapsulation of probiotic bacteria using $\mathrm{pH}$-induced gelation of sodium caseinate and gellan gum. International Dairy Journal, 21(4), 247-253. https://doi.org/10.1016/j.idairyj.2010.11.002 Nagpal, M., Maheshwari, D., Rakha, P., Dureja, H., Goyal, S., \& Dhingra, G (2012). Formulation development and evaluation of alginate microspheres of ibuprofen. Journal of Young Pharmacists, 4(1), 13-16. https://doi.org/10.4103/0975-1483.93573

Nazzaro, F., Fratianni, F., Coppola, R., Sada, A., \& Orlando, P. (2009) Fermentative ability of alginate-prebiotic encapsulated Lactobacillus acidophilus and survival under simulated gastrointestinal conditions. Journal of Functional Foods, 1(3), 319-323. https://doi.org/10.1016/j.jff.2009.02.001

Ng, S. L., Lai, K. W., Nyam, K. L., \& Pui, L. P. (2019). Microencapsulation of Lactobacillus plantarum $299 \mathrm{v}$ incorporated with oligofructose in chitosan coatedalginate beads and its storage stability in ambarella juice. Malaysian Journal of Microbiology, 15(5), 408-418. https://doi.org/10.21161/mjm.190337

Nualkaekul, S., Lenton, D., Cook, M. T., Khutoryanskiy, V. V., \& Charalampopoulos, D. (2012). Chitosan coated alginate beads for the survival of microencapsulated Lactobacillus plantarum in pomegranate juice. Carbohydrate Polymers, 90(3), 1281-1287. https://doi.org/10.1016/j.carbpol.2012.06.073

Piazza, L., \& Roversi, T. (2011). Preliminary study on microbeads production by co-extrusion technology. Procedia Food Science, 1(Icef 11), 1374-1380 https://doi.org/10.1016/j.profoo.2011.09.204

Prakash, S., Tomaro-Duchesneau, C., Saha, S., \& Cantor, A. (2011). The gut microbiota and human health with an emphasis on the use of microencapsulated bacterial cells. Journal of Biomedicine and Biotechnology, 2011, 1-12. https://doi.org/10.1155/2011/981214

Ranadheera, C. S., Vidanarachchi, J. K., Rocha, R. S., Cruz, A. G., \& Ajlouni, S. (2017). Probiotic delivery through fermentation: Dairy vs. non-dairy beverages. Fermentation, 3(4), 1-17. https://doi.org/10.3390/fermentation3040067

Ringel, Y., Ringel-Kulka, T., Maier, D., Carroll, I., Galanko, J. A., Leyer, G., \& Palsson, O. S. (2011). Probiotic bacteria Lactobacillus acidophilus NCFM and Bifidobacterium lactis Bi-07 versus placebo for the symptoms of bloating in patients with functional bowel Disorders. Journal of Clinical Gastroenterology, 45(6), 518-525. https://doi.org/10.1097/MCG.0b013e31820ca4d6

Roberfroid, M., Gibson, G. R., Hoyles, L., McCartney, A. L., Rastall, R., Rowland, I., Wolvers, D., B., W., Szajewska, H., Stahl, B., Guarner, F., Respondek, F., Whelan, K., Coxam, V., Davicco, M.-J., Le'otoing, L., Wittrant, Y., Delzenne, N. M., Cani, P. D., Neyrinck, A. M., \& Meheust, A. (2010). Prebiotic effects: Metabolic and health benefits. Biochemical Pharmacology, 104(2), 72 https://doi.org/10.1017/S0007114510003363

Rodríguez-Huezo, M. E., Durán-Lugo, R., Prado-Barragán, L. A., Cruz-Sosa, F. Lobato-Calleros, C., Alvarez-Ramírez, J., \& Vernon-Carter, E. J. (2007). Preselection of protective colloids for enhanced viability of Bifidobacterium bifidum following spray-drying and storage, and evaluation of aguamiel as thermoprotective prebiotic. Food Research International, 40(10), 1299-1306. 
https://doi.org/10.1016/j.foodres.2007.09.001

Rogers, L., Said, S. S., \& Mequanint, K. (2013). The effects of fabrication strategies on 3D scaffold morphology, porosity, and vascular smooth muscle cell response. Journal of Biomaterials and Tissue Engineering, 3(3), 300-311. https://doi.org/10.1166/jbt.2013.1088

Saarela, M., Virkajärvi, I., Alakomi, H. L., Mattila-Sandholm, T., Vaari, A., Suomalainen, T., \& Mättö, J. (2005). Influence of fermentation time, cryoprotectant and neutralization of cell concentrate on freeze-drying survival, storage stability, and acid and bile exposure of Bifidobacterium animalis ssp. lactis cells produced without milk-based ingredients. Journal of Applied Microbiology, 99(6), 1330-1339. https://doi.org/10.1111/j.1365-2672.2005.02742.x

Sagheddu, V., Elli, M., Biolchi, C., Lucido, J., Morelli, L., Technologies, A. A., Arda, F., \& Cuore, S. (2018). Impact of mode of assumption and food matrix on probiotic viability. Journal of Food Microbiology, 2(2), 2-7.

Sangwan, V., Tomar, S. K., Singh, R. R. B., Singh, A. K., \& Ali, B. (2011). Galactooligosaccharides: Novel components of designer foods. Journal of Food Science, 76(4), R103-R111. https://doi.org/10.1111/j.1750-3841.2011.02131.x

Sathyabama, S., Ranjith kumar, M., Bruntha devi, P., Vijayabharathi, R., \& Brindha priyadharisini, V. (2014). Co-encapsulation of probiotics with prebiotics on alginate matrix and its effect on viability in simulated gastric environment. $L W T$ Food Science and Technology, 57(1), 419-425. https://doi.org/10.1016/j.lwt.2013.12.024

Shinde, T., Sun-Waterhouse, D., \& Brooks, J. (2014). Co-extrusion encapsulation of probiotic Lactobacillus acidophilus alone or together with apple skin polyphenols: An aqueous and value-added delivery system using alginate. Food and Bioprocess Technology, 7(6), 1581-1596. https://doi.org/10.1007/s11947013-1129-1

Shori, A. B. (2017). Microencapsulation improved probiotics survival during gastric transit. HAYATI Journal of Biosciences, 24(1), 1-5. https://doi.org/10.1016/j.hjb.2016.12.008

Siang, S. C., Wai, L. K., Lin, N. K., \& Phing, P. L. (2019). Effect of added prebiotic (isomalto-oligosaccharide) and coating of beads on the survival of microencapsulated Lactobacillus rhamnosus GG. Food Science and Technology, 39, 601-609. https://doi.org/10.1590/fst.27518

Silva, K. C. G., Cezarino, E. C., Michelon, M., \& Sato, A. C. K. (2018a). Symbiotic microencapsulation to enhance Lactobacillus acidophilus survival. LWT - Food Science and Technology, 89, 503-509. https://doi.org/10.1016/j.lwt.2017.11.026

Silva, M. P., Tulini, F. L., Martins, E., Penning, M., Fávaro-Trindade, C. S., \& Poncelet, D. (2018b). Comparison of extrusion and co-extrusion encapsulation techniques to protect Lactobacillus acidophilus LA3 in simulated gastrointestinal fluids. LWT - Food Science and Technology, 89, 392-399. https://doi.org/10.1016/j.lwt.2017.11.008

Smrdel, P., Bogataj, M., \& Mrhar, A. (2008). The influence of selected parameters on the size and shape of alginate beads prepared by ionotropic gelation. Scientia Pharmaceutica, 76(1), 77-89. https://doi.org/10.3797/scipharm.0611-07

Solanki, H. K., Pawar, D. D., Shah, D. A., Prajapati, V. D., Jani, G. K., Mulla, A. M., \& Thakar, P. M. (2013). Development of microencapsulation delivery system for long-term preservation of probiotics as biotherapeutics agent. BioMed Research International, 2013, 1-21. https://doi.org/10.1155/2013/620719

Sultana, K., Godward, G., Reynolds, N., Arumugaswamy, R., Peiris, P., \& Kailasapathy, K. (2000). Encapsulation of probiotic bacteria with alginate-starch and evaluation of survival in simulated gastrointestinal conditions and in yoghurt. International Journal of Food Microbiology, 62(1-2), 47-55. https://doi.org/10.1016/S0168-1605(00)00380-9

Talwalkar, A., \& Kailasapathy, K. (2004). Role of oxygen in the viability of probiotic bacteria. Current Issues in Intestinal Microbiology, 5(1), 1-8.

WHO, \& FAO. (2002). Guidelines for the evaluation of probiotics in food. London Ontario, Canada.

Yang, Y. X., He, M., Hu, G., Wei, J., Pages, P., Yang, X. H., \& Bourdu-Naturel, S. (2008). Effect of a fermented milk containing Bifidobacterium lactis DN173010 on Chinese constipated women. World Journal of Gastroenterology, 14(40), 6237-6243. https://doi.org/10.3748/wjg.14.6237

Yee, W. L., Yee, C. L., Lin, N. K., \& Phing, P. L. (2019). Microencapsulation of Lactobacillus acidophilus NCFM incorporated with mannitol and its storage stability in mulberry tea. Ciência e Agrotecnologia, 43, e005819. https://doi.org/10.1590/1413-7054201943005819

Yong, A. K. L., Lai, K. W., Ghazali, H. M., Chang, L. S., \& Pui, L. P. (2020) Microencapsulation of Bifidobacterium animalis subsp. lactis BB-12 with mannitol. Asia-Pacific Journal of Molecular Biology and Biotechnology, 28(2), 32-42. https://doi.org/10.35118/apjmbb.2020.028.2.04

Yu, W. K., Yim, T. Bin, Lee, K. Y., \& Heo, T. R. (2001). Effect of skim milkalginate beads on survival rate of bifidobacteria. Biotechnology and Bioprocess Engineering, 6(2), 133-138. https://doi.org/10.1007/BF02931959

Zam, W., Bashour, G., Abdelwahed, W., \& Khayata, W. (2014). Alginatepomegranate peels' polyphenols beads: Effects of formulation parameters on loading efficiency. Brazilian Journal of Pharmaceutical Sciences, 50(4), 741-748. https://doi.org/10.1590/S1984-82502014000400009

Zanjani, M. A. K., Tarzi, B. G., Sharifan, A., \& Mohammadi, N. (2014). Microencapsulation of probiotics by calcium alginate-gelatinized starch with chitosan coating and evaluation of survival in simulated human gastro-intestinal condition. Iranian Journal of Pharmaceutical Research, 13(3), 843-852. https://doi.org/10.22037/ijpr.2014.1550 